\title{
Financial Stability in Developing Economy: Role of Financial Inclusion and Financial Efficiency
}

\author{
Rahman Olanrewaju Raji \\ Canterbury International High School, Lekki-Ajah, Nigeria
}

\begin{abstract}
This paper explores the asymmetric nexus between financial inclusion, financial efficiency and financial stability, within asymmetric and symmetric Autoregressive Distributed Lag (NARDL) framework, covering the period from 2003 to 2018 , using quarterly data in Nigeria. The findings showed that symmetric technique of econometric test detects, that financial stability is augmented by better improvement in financial inclusion in short-run, while asymmetric technique observed that short-run positive effect, and negative effect likewise long-run decrease in this index heightened the level of financial stability in this economy. This study further found trade-off existence, between financial efficiency and financial stability in both symmetric and asymmetric techniques of econometric tests, which is consistent with some empirical findings. The results based on the model and empirical data indicate that, the monetary authority needs to follow prudent and adequate supervisory standard in pursuing financial inclusion, financial intermediaries should be accompanied with good institutional quality, including financial awareness that should be enhanced through financial teachings in all sectors both in the urban and rural areas of the economy.
\end{abstract}

Keywords: financial efficiency; financial inclusion; financial stability; NARDL

\section{Introduction}

An economy with healthy macroeconomic management has certainly, established a realistic foundation towards a sustainable macroeconomic environment. Most emerging and developing economies are associated with persistent and widening income inequality and poverty increase despite, high records of economic growth and improved financial development in most of these economies. These growth rates could be attributed to the actions of a minority of the economic agents in this societies. Consequently, the distribution of the benefits or gains from economic growth, and improved financial development have been restricted to a small segment of the economies. These hinder the success of achieving macroeconomic goals, which could jeopardize sustainable macroeconomic environment.

However, the extent of sustainability of an economy depends on macroeconomic stability, which in turn, relies on the state of financial stability. An economy with sound and stable financial system tends to function efficiently and effectively, where the allocation of funds spurs and stimulates sustainable economic growth; the success of macroeconomic stability hinges on the condition that, financial sector guarantees efficient and effective allocation of savings and investment, towards a sustainable inclusive growth. To ensure inclusive growth, quality of finance, including institutional quality are relevant and significant for economic development, which are key drivers of inclusive growth in any economy. The impact of finance on inclusive growth via financial inclusion or financial expansion is regarded as a paramount and inevitable means, by which economic growth performance could promote and assure inclusiveness. Emerging and developing economies are advised to promote financial inclusion, because sound financial inclusion acts a primary and supporting source of finance. This source of finance provides and enhances small and medium businesses with working capital. In addition, it overcomes an obstacle for market to

\footnotetext{
* Corresponding author.

E-mail address: rahmandole@gmail.com (Rahman Olanrewaju Raji)
} 
operate, in favour of the underprivileged and the poor as well as attracting the unbanked into the formal financial system. Without discrimination, this would result to adequate access to a range of financial services or products at a fair price, right time and right place. By implication, financial inclusion encourages financial stability through improved process of financial intermediation between savings and investment. An effective and sound financial inclusion in an economy connects individuals in the society into the mainstream, making the transmission mechanism of monetary policy effective, which could contribute to greater financial stability and foster financial efficiency, in the economy. The failure to recognize and identify the strategies, and measures to design towards initiating an effective financial inclusion, by the policy planners and authority of financial institutions in the economy; a poor and ineffective financial inclusion continues to devastate financial system or financial intermediation, which could hinder financial performance and efficiency in the economy. Lack of efficient regulatory institutions and unreliable legal framework toward uncompromised financial extension tends to devastate economic sustainability; these ineffective checks and balances could generate misallocation of funds, financial exclusion and the overall adverse impact, loss of inclusive growth and development, which in turn, escalate unemployment and inequality in the society at large.

There are lots of studies assessing the nexus in which financial inclusion could spur or impact financial stability, without much empirical supports, whereas a strand of studies on the simultaneous effect of financial inclusion and efficiency on financial stability is very scanty. This study explores asymmetric technique, unlike symmetric approach employed by most existing studies. The asymmetric ARDL approach is adopted in order to identify the effects of negative shock from a variable, which may be differed from the effect of positive shock in both sign and magnitude, such could provide useful information to monetary authority and other financial related authorities in Sub-Saharan Africa, and Nigeria's cases has been much less studied. Moreover, this study distinguishes the asymmetric effects of financial inclusion and efficiency on financial stability in the short and long run. In addition, the study incorporates relevant variables such inclusive growth, and monetary policy in order to avoid omission of variable bias.

\section{Empirical Review}

Based on the empirical studies, there is a connection between financial inclusion and financial sustainability. One leading key factor receiving an interesting attention is either the effect of financial inclusion on financial stability or determinants of financial inclusion or financial inclusion-inequality nexus. Recently, few studies disclosed linkages between financial inclusion-financial stability nexus. Studies like Barik et.al(2020),Pham et.al(2020), Jimoh et.al (2019),Le et.al (2019), Neaime and Gaysset (2018), Siddik et.al (2018), Al-Smadi (2018) ,Morgan and Pontines (2014) are among the few empirical studies, that have conducted findings on impact of financial inclusion on financial stability.

Le et.al (2019) examined the impact of financial inclusion in Asia on financial efficiency and financial sustainability. A sample of 31 Asian countries were employed in the study, during the period spanning from 2004 to 2016, using Feasible Generalized Least Squares (FGLS). Their estimates unveiled a growing financial inclusion inversely impacted financial efficiency while favourably influenced financial sustainability. In a similar findings by Pham et.al (2020) exploring the relationship between financial inclusion and financial stability, under the scope of Asian economies through the Feasible Generalized Least Squares (FGLS) regression. The empirical findings exhibited that, there was an overall tendency of weak positive influence of financial inclusion on financial stability. El Said et.al(2018) informed that, using panel regressions for 67 countries over the period 2000-2014, there could be significant policy trade-offs existing between financial inclusion and financial stability in both Advanced Economies (AEs) and Emerging Markets (EMs)

Neaime and Gaysset (2018) examined empirically the effect of financial inclusion on financial stability, using data of eight MENA countries, during the period from 2002 to 2015. The results found a significant and positive relationship between financial inclusion measured by the number of banks per 100,000 adults and financial stability measured by the standard deviation of the growth rate of deposits. Neaime and Gaysset (2018) contradicted Barik et.al(2020), who investigated the impact of financial inclusion on financial stability among the BRICS countries, using the system Generalized Method of Moments (GMM). Their findings depicted that financial inclusion had a negative and significant effect on financial stability. These were attributed to rapid expansion of credit to the private sectors, 
erosion of credit standards of the banks, including difficulties in credit assessment, increase in non-performing assets, as well as credit defaults of the borrowers and inadequate supervision of the banking sector.

Morgan and Pontines (2014) assessed the link between financial inclusion and financial stability, by exploring data for the period 2005-2011 and the GMM dynamic panel estimator technique. The results showed that, financial inclusion had a positive effect on financial stability (i.e.banks' $Z$ score) and was negatively related to non-performing loans. The greater number of SMEs also led to a lower probability of default and also caused lower non-performing loans (NPLs). Siddik et.al (2018) was consistent with Morgan and Pontines (2014), when similar study was carried out, the effect of financial inclusion on financial stability, adopting GMM dynamic panel model on panel data from 2001-2013. The outcome was that financial inclusion proxy by ratio of SME loans outstanding and ratio of SME borrower to total borrower, had a significant and positive relation with financial stability proxy by the bank Z-score and monetary indicators- private credit to GDP and liquidity were positively related to financial stability. In validating Siddik et.al (2018) and Morgan and Pontines (2014), Dienillah and Anggraeni (2016) established that, financial inclusion had registered a positive nexus with the financial system stability by ensuring a decrease in nonperforming loans. This had increased portion of the credit for SMEs and reduction in poor loans

Han and Melecky (2013) tested the financial inclusion - stability relationship in 95 countries with the aid of World Bank data and cross-sectional regressions method. The conclusion was that financial inclusion (broader access to and use of bank deposits) enhanced banks' proportion of stable funding, and mitigated total bank deposit volatility in times of economic recessions, implying a promoted financial stability in both the banking system and financial sector as a result of effective financial inclusion. Lenka and Bairwa (2016) agreed with Han and Melecky (2013) that financial inclusion on monetary policy was highly significant, when a study conducted on South Asian Association for Regional Cooperation countries from 2004-2013. An improved financial inclusion might reduce the inflation rate in an economy, which ensured price stability level in the region. Evans (2016) stated in his findings that a long-run relationship existed between financial inclusion and monetary policy and existence of a one-way causality from monetary policy effectiveness to financial inclusion. It implied monetary policy effectiveness was the driver of financial inclusion.

Sahaye et al. (2015) analyzed the relation between inclusion and stability from 2004-2011, using number of borrowers per 1,000 adults as a proxy for financial inclusion, and bank z-score as a proxy for financial stability. The estimates panel regression found that, higher financial inclusion led to a decrease in the bank z-score. Consequently, higher instability in the financial system emerged. While higher level of banking system supervision led to a higher bank z-score and a more stable financial system. Aahmed et.al(2017) deviated from Sahay et al. (2015), which tested the relationship between financial inclusion and banking stability, exploring 2635 banks in 86 countries from 20042012. Their findings showed that financial inclusion was positively related to banks stability, where the banks had lower marginal costs, higher shares of customer deposit funding, and countries with better quality of institutions.

Al-Smadi (2018) studied the effect of financial inclusion and financial stability in Jordan by applying Fully Modified Least Squares technique on time series data from 2006 to 2017. The results showed presence of a weak significant and positive impact of financial inclusion on the financial stability. This was not in conformity with Widarwati et.al (2019). Their study examined the relationship of financial inclusion and financial stability in Indonesia's Sharia banking. Financial inclusion (access to financial services) and financial stability of Sharia banking proxy by Non Performing Financial (NPF) during the study period from 2011 to 2016, using regression test. The results of study found that the deposits as proxy of financial inclusion had a positive effect to stability of financial institution, whereas Jimoh et.al (2019) investigated the nexus between financial inclusion instruments and performance of Nigerian banks. The regression analysis revealed positive and significant impact of automated teller machines, bank embranchment, and point of sale terminals on bank performance, except the number of bank account.

In conclusion, most empirical assessment of the nexus between financial inclusion and financial stability happened to be mixed outcomes. Most studies could be characterized by omission of relevant control variables as intervening indicators, absence of concrete index as measure of both financial inclusion and financial stability, including adoption of linear approach of econometric test. This study tends to correct weakness of existing studies, by exploring a comprehensive index that incorporates multidimensional index of financial inclusion, financial efficiency and financial stability, in which intervening relevant indicators (inclusive growth and monetary policy) are inclusive into 
the model. Specifically, asymmetric approach of ARDL model is employed in order to determine, whether increases and decreases in financial inclusion, and financial efficiency have symmetric or asymmetric impacts on financial stability.

\section{Model Specification}

This study assesses whether financial inclusion and financial efficiency could have effect on the financial stability, and enhance growth inclusive. Our estimation is not linked directly to any existing theory, but to incorporate key variables into our model specification. Based on the research variables, the generalized form of the study model can be represented as follows:

$\begin{array}{ccccc}\text { Financial stability } & = & \text { Core Variables } & + & \text { Control Variables } \\ F S & = & X & + & C V\end{array}$

where the core variables include financial inclusion (FI) and financial efficiency (E), then the control variable comprises of inclusive growth (IG) and monetary policy (MP). Monetary policy is a monetary variable, which has direct or indirect impact on most financial parameters, including financial stability while inclusive growth is classified as a parameter, which is attributed to be the consequence of effective effect of better financial development in the economy via sound financial inclusion.

After transforming eq.1 into linear equation, it is represented as follows:

$$
F S_{\mathrm{t}}=\alpha_{0}+\alpha_{1} X_{\mathrm{t}}+\alpha_{2} C V_{\mathrm{t}}+\varepsilon_{\mathrm{t}}
$$

All the variables in equation (2) such as FS, X and CV are defined above, $\alpha_{1}$ and $\alpha_{2}$ represent long run elasticity, and $\varepsilon_{t}$ is the error correction term. Therefore, equation (2) indicates the long run effect on financial stability from a set of explanatory variables. To estimate long run co-integration and short run elasticity in the model, the study explores cointegrated test.

For empirical estimation, our study utilizes asymmetric or nonlinear autoregressive distributive lag (NARDL) model developed by Shin et al. (2011). This technique is relevant in our study as a result of its ability to distinguish, between linear and nonlinear co-integration unlike most existing techniques, which presume linear or symmetric effects of the movement of explanatory variables, on a dependent variable. This study follows this technique to asses, if a positive change and negative change in explanatory variables of the study have different effects on the dependent variable.

To develop full representation of the NARDL approach towards estimation of a nonlinear model, to capture the asymmetric effect of core variables (financial inclusion and financial efficiency) of study on the financial stability, the linear equation (2) is converted into asymmetric long-run regression of financial stability, which is specified as shown:

$$
F S_{\mathrm{t}}=\alpha_{0}+\alpha_{11}^{-} X_{\mathrm{t}}^{-}+\alpha_{12}^{+} X_{\mathrm{t}}^{+}+\alpha_{2} C V_{\mathrm{t}}+\varepsilon_{\mathrm{t}}
$$

From equation (3), the movement in core variables, $X_{t}$ are decomposed into its positive and negative partial sum i.e. $X_{\mathrm{t}}=X_{\mathrm{t}}^{-}+X_{\mathrm{t}}^{+}$where $X_{\mathrm{t}}^{-}$and $X_{\mathrm{t}}^{+}$are the partial sum of the negative change (a decrease in core variables) in $X_{\mathrm{t}}$ and sum of the positive change (an increase in core variables) in $X_{t}$ respectively. The formulation of partial sums of positive and negative changes is:

$$
\begin{aligned}
& X_{\mathrm{t}}^{+}=\sum_{\mathrm{i}=0}^{\mathrm{t}} \Delta X_{\mathrm{t}}^{+}=\sum_{\mathrm{i}=0}^{\mathrm{t}} \max \left(\Delta X_{\mathrm{t}}, 0\right) ; \\
& X_{\mathrm{t}}^{-}=\sum_{\mathrm{i}=0}^{t} \Delta X_{\mathrm{t}}^{-}=\sum_{\mathrm{i}=0}^{t} \min \left(\Delta X_{\mathrm{t}}, 0\right) ;
\end{aligned}
$$


where $X_{t}^{+}$indicates partial sum of a positive set of core variables: $F I_{t}^{+}+E_{t}^{+}$and $X_{t}^{-}$shows partial sum of a negative set of core variables: $\mathrm{FI}_{\mathrm{t}}^{-}+\mathrm{E}_{\mathrm{t}}^{-}$respectively, which have already been defined above. The parameters in equation (3) like $\alpha_{11}^{+}$captures the long-run effects, between financial stability and its exogenous increase $\left(X_{t}^{+}\right)$. Besides that, $\alpha_{11}^{-}$captures the long-run relation between financial stability and its exogenous reduction, $\left(X_{t}^{-}\right)$.

Shin et al. (2011) established that the asymmetric effect of exogenous variable on the endogenous variable exists, if the magnitude of exogenous increase of such variable has a significant different than the magnitude of exogenous reduction of the variable. Where the findings display $\alpha_{11}^{+}=\alpha_{11}^{-}$then the asymmetric pass-through effects from core variables (financial inclusion and financial efficiency) to financial stability will not exist. Essentially, the equation (3) is extended as shown in Shin et al. (2011), which can be framed in an ARDL setting along the line of Pesaran and Shin (1999) and Pesaran et al. (2001) as:

$$
\begin{aligned}
F S_{\mathrm{t}}=\gamma_{0} F S_{\mathrm{t}-1} & +\gamma_{1}^{+} X_{\mathrm{t}-1}^{+}+\gamma_{1}^{+} X_{\mathrm{t}-1}^{+}+\gamma_{7} C_{\mathrm{t}-1}+\sum_{j=1}^{p-1} \theta_{1} \Delta F_{\mathrm{t}-j}+\sum_{j=0}^{\mathrm{q}-1}\left(\beta_{j}^{+} \Delta X_{\mathrm{t}-j}^{+}+\beta_{\mathrm{t}-j}^{-} \Delta X_{\mathrm{t}-j}^{-}\right) \\
+ & +\sum_{j=0}^{r-1} \theta_{1} \Delta C_{\mathrm{t}-j}+\varepsilon_{\mathrm{t}}
\end{aligned}
$$

where $\Delta$ indicates the first difference and $\rho-1, \mathrm{q}-1$ and $\mathrm{r}-1$ are the lag lengths. Equation (6) is the empirical model, which this study tends to estimate to test the long run relationship between the candidate variables; financial inclusion and financial efficiency and independent variable, financial stability.

Based on the assumption of linearity, this study introduces the possibility of nonlinearity in modeling the relationship. Since all parameters contained in equation (6) are linear which allows estimation of model using standard ordinary least square (OLS) method. The unrestricted specification of NARDL error correction model in equation (6) proclaims to have two different types of asymmetry; short and long-run asymmetries. To gauge both long-run and short-run asymmetric tests, the study runs the Wald test. (See Shin, et al., 2011). The long-run nonlinearity model with the null hypothesis of a linear long run relationship is tested through $\gamma_{1}^{+} \delta+=\gamma_{1}^{-}$while the short-run nonlinearity model in which the null hypothesis of additive linearity is tested through $\sum_{j=0}^{p-1} \beta_{j}^{+}=\sum_{j=\mathbb{0}}^{p-1} \beta_{j}^{-}$. According to Shin et al.(2014), long-run co-integration with the aid of estimated NARDL can be confirmed, using the bounds test approach applicable by comparing the f-statistic (Wald test) and the critical value, as proposed by Pesaran et al. (2001). The null hypothesis is $0 \gamma_{0}=\gamma_{1}^{+}=\gamma_{1}^{+}=\gamma_{7}=0$.

To further assess the relationship between financial inclusion and financial efficiency and financial stability, we carry out symmetric ARDL and compare the outcomes with asymmetric ARDL for better policy implication. All the variables were in their logarithm form to avoid measurement error and attain reliable estimates

\section{Variables and Sources of Data}

The study is conducted, using quarterly data over 2003/first quarter to 2018/fourth quarter period. The data were converted into quarterly data using e-view package. The study constructs comprehensive indexes for our candidate variables of interest, by incorporating multidimensional index of financial stability, financial inclusion and financial efficiency. To construct financial stability indicator, our study adopts three dimensions, which consist bank Z-score, bank credit to bank deposits (\%) and liquid assets to deposits and short-term funding (\%). To construct financial efficiency indicator, three dimensions are used, which include bank net margin (\%), return on assets (\% after tax) and return on equity (\%, after tax. Our study follows Sarma (2008) methodology for financial inclusion, who he developed financial inclusion index, using three dimensions of financial inclusion. This comprises accessibility dimension, availability dimension and usage dimension of banking service. Each dimension was measured by an indicator as availability indicates Number of branches of commercial banks per 100,000 adults, accessibility suggests number of deposit accounts with commercial banks per 1,000 adults and usage indicates outstanding loans with commercial banks (\% of GDP). Our control variables include monetary policy indicator proxy with inflation rate in the economy and inclusive growth. Following World Bank (2014), inclusive growth variable can be proxy with the 
growth rate of inequality adjusted human development index (IHDI) i.e. $100 \times\left(\mathrm{HDI}_{(-1)}-\mathrm{HDI}\right) /(\mathrm{HDI})$. The human development index (HDI) is defined as the mean of achievements in the following three principal categories which are decent living standards, knowledge and long life and health. The proxy is better for inclusive growth, having integrated pro-poor ameliorations in social opportunities, and equal access to economic opportunities. All data are sourced from World Development Indicators except inclusive growth sourced from UNDP database.

More importantly, the following steps are adopted to derive our index, for instance, financial inclusion index. Firstly, we calculate the yearly dimension index of each FI dimension before quarterly conversion, using the following formula:

$$
D I i=(A i-M I N i) /(M A X i-M I N i)
$$

where DIi is the dimension index of dimension $\mathrm{i}, \mathrm{Ai}$ is the actual value of dimension $\mathrm{i}$, Mini is the minimum value of dimension i, and Maxi is the maximum value of dimension i. Then, the yearly FI before quarterly conversion is measured as follows:

$$
F I=1-\frac{\sqrt{(1-A)^{2}+(1-A C)^{2}+(1-U)^{2}}}{\sqrt{3}}
$$

where $\mathrm{A}, \mathrm{AC}$, and $\mathrm{U}$ denote the dimension index for the availability, accessibility and usage dimensions, respectively. The value of FI ranges from 0 , which indicates low FI, and 1, which indicates high FI.

The yearly FS before quarterly conversion is measured as follows:

$$
F I=1-\frac{\sqrt{(1-A)^{2}+(1-A C)^{2}+(1-U)^{2}}}{\sqrt{3}}
$$

where $\mathrm{A}, \mathrm{AC}$, and $\mathrm{U}$ denote the dimension index for the availability, accessibility and usage dimensions, respectively. The value of FI ranges from 0, which indicates low FI, and 1, which indicates high FI. This was also applied to other indicators like financial stability index and financial efficiency index in this study.

\section{Empirical Results}

Although ARDL and NARDL do not require a data pretesting before estimation of the data using either ARDL or NARDL, this study determines the order of integration of all the data. The table 1 below shows the results of the Augmented Dickey-Fuller (ADF) unit root tests for the order of integration of the variables under finding. The results of the Augmented Dickey-Fuller (ADF) unit root test revealed the stationarity properties of selected variables, considering the intercept without the trend properties that, with the exception of financial efficiency indicator, all other variables are not characterized by the unit root at level and that all the variables exhibited evidence of stationarity at first difference, mostly at a one percent significance level. The conclusion is that all the variables are integrated of order 1, which lend support to the use of both ARDL and NARDL.

Table 1. Unit Root Test Results (ADF Test)

\begin{tabular}{cccccc}
\hline Variables & E & FS & FI & MP & IG \\
\hline Level & -2.96 & -1.57 & -1.92 & -2.02 & -0.80 \\
$1^{\text {st }}$ Diff. & -6.12 & -5.08 & -7.21 & -7.49 & -8.72 \\
\hline
\end{tabular}

However, to identify a long-run association, the study applies the ARDL bounds testing approach proposed by Pesaran et al. (2001) under the symmetric assumption where financial stability serves as the dependent variable. To test for symmetric co-integration via F statistical test by employing the Wald test. As for F-test, the null hypothesis of no co-integration had been tested for the model. The results are as tabulated in Table 2 indicating, that the F-statistics for the model was larger than the upper bound and the lower bound values of $1 \%$ significant level. Hence, the null hypothesis of no co-integration is rejected, this had verified the presence of long run co-integration in this model 
Table 2. Bound Testing (ARDL)

\begin{tabular}{ccl}
\hline F- statistic & 7.03 & \\
\hline Critical values for F-statistics & Lower I $(0)$ & Upper I $(0)$ \\
\hline $10 \%$ & 2.45 & 3.52 \\
$5 \%$ & 2.56 & 4.01 \\
$1 \%$ & 3.74 & 5.06 \\
\hline
\end{tabular}

For the long run estimates as tabulated in table 3, the candidate explanatory variables (financial inclusion and financial efficiency) display positive effects on financial stability. These candidate variables were not statistically significant, but control variables (inflation and inclusive growth) were statistically significant. The results show, a one percent increase in monetary policy improvement could promote financial stability and a one percent increase in inclusive growth would have adverse effect on financial stability.

Table 3. Long Run Estimate of ARDL

\begin{tabular}{cccc}
\hline Variables & Coefficient & t-statistic & Prob. \\
\hline E & 0.193813 & 0.961324 & 0.3464 \\
FI & 0.224715 & 0.814220 & 0.4239 \\
IG & -7.470256 & -9.905907 & $0.0000^{* * *}$ \\
MP & 0.012978 & 1.423576 & $0.1680^{*}$ \\
\hline
\end{tabular}

The short-run estimates in table 4 indicate that, the coefficient of the error correction term $\operatorname{ECM}_{(\mathrm{t}-1)}$ suggests the speed of adjustment toward long-run equilibrium from any short-run shock in the independent variables. The error correction term is negative and statistically significant. The short-run estimates found that the impact of current financial efficiency on financial stability was negatively associated and that the effect of current financial inclusion on financial stability was positively related. The candidate variables of interest are statistically significant at 10 percent level while control variables showed similar outcomes like long-run estimates of the model.

Table 4. Short-Run Estimates of ARDL

\begin{tabular}{cccc}
\hline Variables & Coefficient & $\mathrm{t}$-statistic & Probability \\
\hline$\Delta \mathrm{E}$ & -0.222794 & -1.709316 & $0.1009^{*}$ \\
$\Delta \mathrm{E}_{(\mathrm{t}-1)}$ & -0.000000 & -0.000000 & 1.0000 \\
$\Delta \mathrm{FI}$ & 0.638907 & 1.775965 & $0.0890^{*}$ \\
$\Delta \mathrm{FI}_{(\mathrm{t}-1)}$ & 0.000000 & 0.000000 & 1.0000 \\
$\Delta \mathrm{IG}$ & -20.812619 & -4.011274 & $0.0005^{* * *}$ \\
$\Delta \mathrm{IG}_{(\mathrm{t}-1)}$ & -0.000000 & -0.000000 & 1.0000 \\
$\Delta \mathrm{MP}$ & 0.012347 & 2.012550 & $0.0560^{* *}$ \\
$\mathrm{ECM}_{(\mathrm{t}-1)}$ & -1.023311 & -5.411502 & $0.0000^{* * *}$ \\
\hline
\end{tabular}

Note: $(*),(* *)$, and $(* * *)$ indicate $10 \%, 5 \%$ and $1 \%$ significance level respectively

Table 5 reports the model residual diagnostic tests, which include test of Autocorrelation, a test of Heteroscedasticity and the RESET test of model estimation robustness and stability. The outcomes of these residual diagnostic tests indicate that the Test of Autocorrelation estimation confirms free from serial correlation, and test of Heteroscedasticity ascertains that there is no ARCH effects. On the other hand, the RESET test confirms model construction validity of this study and the coefficient of adjusted $\mathrm{R}^{2}$ explains the model capability, whose coefficient is significantly high with 71 percent. In addition, Figure 1 represent CUSUM and CUSUMSQ tests of this model. The figures show that our model passed the CUSUM test, whereas the CUSUMQ graph has shown that our model deviated from the test, as the significant lines crossed the critical lines. This implies instability in the model. In order to check the robustness of our study, the study further applies asymmetric ARDL in order to validate our model and findings. 
Table 5. Diagnostic Test

\begin{tabular}{lc}
\hline Serial correlation (LM) Test & $4.68(0.0298)$ \\
Heteroskedasticity Test (BPG) & $0.46(0.9788)$ \\
RESET Test & $0.21(0.8377)$ \\
$\mathrm{R}^{2}$ & $0.710 \mathrm{r} 71 \%$ \\
Normality Test & $23.13(0.0000)$ \\
\hline
\end{tabular}
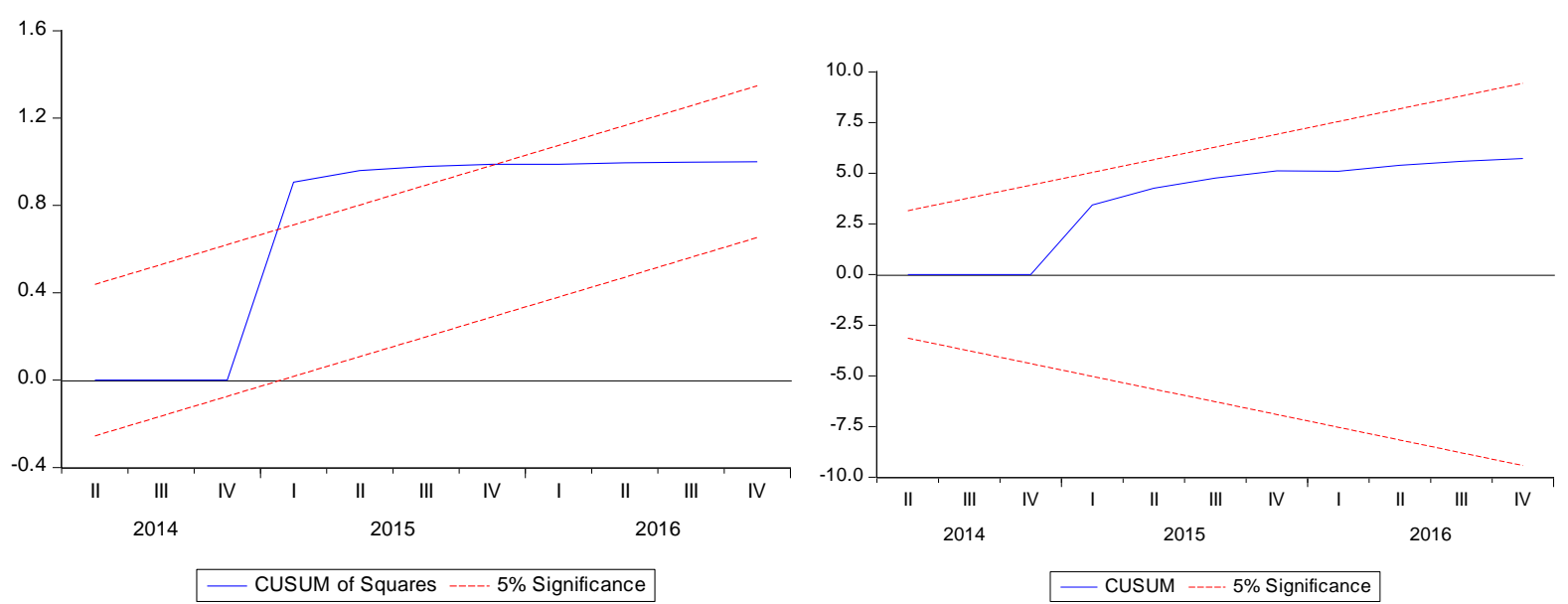

Fig. 1 CUSUM and CUSUMSQ graph of ARDL model

Since the linear ARDL model exhibits that the financial inclusion and financial efficiency are correlated with the financial stability linearly, the study modified these variables to become nonlinear. Following Shin et al. (2011), the study estimated the equation associated with nonlinear ARDL model, by employing the same technique used in the linear ARDL model. The study estimated the asymmetric co-integration via F statistical test by employing the Wald test. The results are as tabulated in Table 6, indicating that the F-statistics for the model was larger than the upper bound and the lower bound values of $1 \%$ significant level. This also verified the presence of long run co-integration in the model.

Table 6. Bound Test for Asymmetric Co integration

\begin{tabular}{cll}
\hline F- statistic & 5.07 & \\
\hline Critical values for F-statistics & Lower $\mathrm{I}(0)$ & Upper $\mathrm{I}(0)$ \\
\hline $10 \%$ & 1.75 & 2.87 \\
$5 \%$ & 2.04 & 3.24 \\
$1 \%$ & 2.56 & 4.05 \\
\hline
\end{tabular}

Table 7 reports the model residual diagnostic test. The residual diagnostic tests indicate that the Test of Autocorrelation estimation confirms free from serial correlation, and Test of Heteroscedasticity discloses that there is no ARCH effects. On the other hand, the RESET test confirms model construction validity of this study and the coefficient of adjusted $\mathrm{R}^{2}$ explains the model capability, whose coefficient is significantly high with 75 percent. In addition, Figure 2 represent CUSUM and CUSUMSQ tests of this model. The figures show that, our model passed the CUSUM test, including the CUSUMQ graph has shown that our model fell within the critical bounds of 5\% significance. 
Table 7. Diagnostic Test

\begin{tabular}{ll}
\hline Serial correlation (LM) Test & $1.34(0.2837)$ \\
Heteroskedasticity Test (BPG) & $3.18(0.2837)$ \\
RESET Test & $0.64(0.523)$ \\
$\mathrm{R}^{2}$ & 0.74 \\
Normality Test & $1.46(0.4826)$ \\
\hline
\end{tabular}
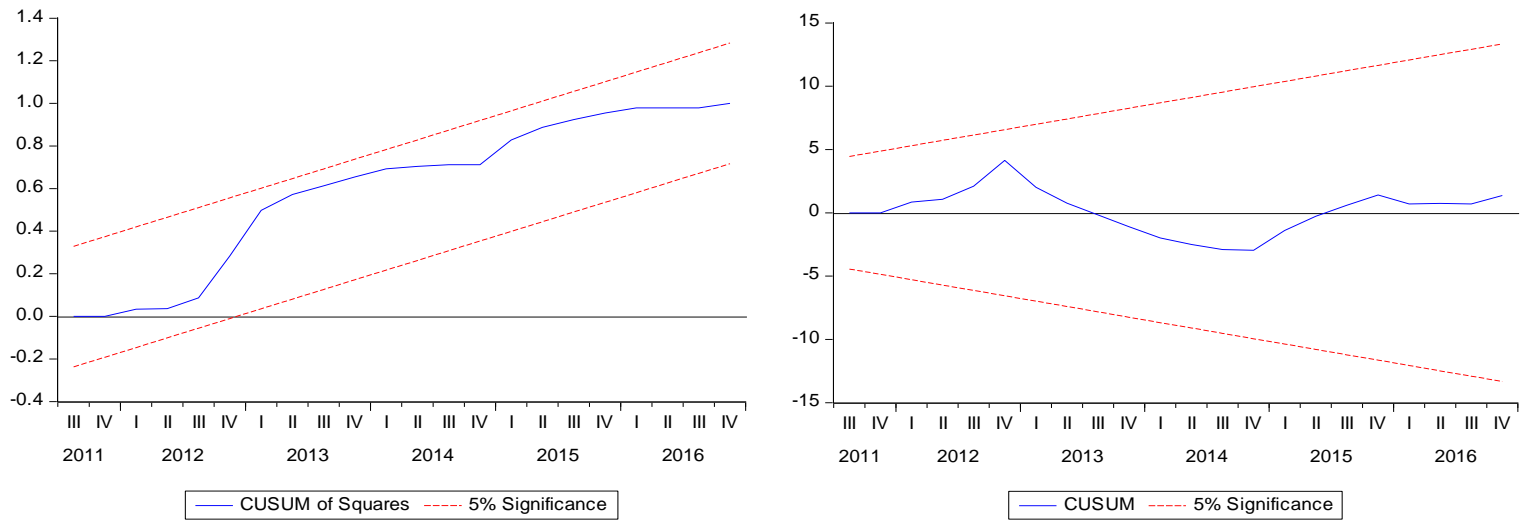

Figure 2. CUSUM and CUSUMSQ graph of NARDL Model

The result as presented in Table 8 shows asymmetric short-run and long run relations between financial inclusion, financial efficiency and financial stability. In the asymmetric long-run, a 10 percent positive and significant relationship existed between a negative shock in financial inclusion and financial stability. It implies that, a one percent increase in negative shock in financial inclusion ensures 1.8 percent increase in financial stability in the economy. On the other hand, a positive relationship was displayed between a positive shock in financial inclusion and financial stability without a significant relationship. The positive shock in financial efficiency reveals positive coefficient in relation to financial stability, while a negative shock in financial efficiency depresses financial stability both displayed absence of statistical significance. In addition, coefficient of monetary policy is positive and significant at ten percent significance level. It implies that, a one percent increase in monetary policy in the economy heightens the level of financial stability by 0.08 percent, whereas inclusive growth also shows a positive and significant impact on the financial stability at one percent significance level. A one percent rise in growth inclusive promotes the financial stability by 0.84 percent in this economy.

Table 8. Asymmetric ARDL Result

\begin{tabular}{lccl}
\hline Variable & Coefficient & t-statistic & Probability \\
\hline$\Delta \mathrm{FS}_{(\mathrm{t}-1)}$ & 0.063 & 0.495 & 0.6248 \\
$\Delta \mathrm{E}^{-}$ & -0.607 & -2.746 & $0.0112^{*}$ \\
$\Delta \mathrm{E}_{(\mathrm{t}-1)}$ & -0.310 & -1.238 & 0.2276 \\
$\Delta \mathrm{E}^{+}$ & 0.198 & 1.204 & 0.2402 \\
$\Delta \mathrm{E}^{+}$ & 0.155 & 0.981 & 0.3363 \\
$\Delta \mathrm{FI}^{-}$ & 1.910 & 1.932 & $0.0652^{*}$ \\
$\Delta \mathrm{FI}_{(\mathrm{t}-1)}^{-}$ & -0.057 & -0.067 & 0.9465 \\
$\Delta \mathrm{FI}^{+}$ & 0.459 & 1.453 & $0.1591^{* *}$ \\
$\Delta \mathrm{FI}^{+}$ & 0.402 & 1.309 & 0.2026 \\
$\Delta \mathrm{IG}^{+}$ & -7.585 & -1.949 & $0.0630^{*}$ \\
$\Delta \mathrm{IG}_{(\mathrm{t}-1)}$ & -5.601 & -1.367 & $0.1842^{*}$ \\
$\Delta \mathrm{MP}$ & 0.007 & 1.188 & 0.2462 \\
$\mathrm{E}_{(\mathrm{t}-1)}^{-}$ & -0.149 & -0.769 & 0.4491 \\
\hline
\end{tabular}




\begin{tabular}{lcll}
\hline Variable & Coefficient & t-statistic & Probability \\
\hline $\mathrm{E}^{+}{ }_{(\mathrm{t}-1)}$ & 0.037 & 0.298 & 0.7680 \\
$\mathrm{FI}^{(\mathrm{t}-1)}$ & 1.824 & 2.338 & $0.0280^{* *}$ \\
$\mathrm{FI}_{(\mathrm{t}-1)}$ & -0.175 & -1.111 & 0.2773 \\
$\mathrm{IG}_{(\mathrm{t}-1)}$ & 0.824 & 4.085 & $0.0004 * * *$ \\
$\mathrm{MP}$ & 0.008 & 2.092 & $0.0472^{*}$ \\
$\mathrm{FS}$ & -0.668 & -5.093 & $0.0000^{* * *}$ \\
Wald Test SR & & Wald Test LR & \\
$\mathrm{E}$ & $0.15(0.878)$ & $\mathrm{E}$ & $0.73(0.712)$ \\
$\mathrm{FI}$ & $1.73(0.098)^{* *}$ & $\mathrm{FI}$ & $1.74(0.095)^{* *}$ \\
\hline Note: & $(*),(* *)$, and $(* * *)$ indicate $10 \%, 5 \%$ and $1 \%$ significance level respectively
\end{tabular}

The asymmetric short-run estimation is indicated in Table 8. The positive and negative effects of the financial inclusion including increase the size of financial stability, which are statistically significant. A one percent rise in both positive effect and negative effect of financial inclusion stimulate the level of financial stability by 0.5 percent and 1.9 percent respectively. The Wald symmetric tests are also explored in determining, whether the differences in the positive and negative coefficient of financial inclusion. From the financial efficiency, its positive effect has direct impact on the financial stability without statistical significance, whereas its negative effect records a negative relationship with the financial stability at 10 percent significant level. It indicates that a one percent increase in negative effect of financial efficiency escalates financial instability.

Consequently, comparative outcomes of the models suggest that asymmetric ARDL approach is much better than that of symmetric ARDL approach. Most of the diagnostic tests, such serial correlation test, heteroskedasticity test, RESENT test, normality test, including $\mathrm{R}^{2}$ associated with asymmetric approach implies that the model is well specified. Model stability further revealed that the CUSUM and CUSUM of squares of recursive residuals tests are stables as the values fall inside the critical bands at 5\% level (Figure 3 and Figure 4), unlike linear ARDL approach. These outcomes of asymmetric ARDL estimation proven strong evidences that the exploration of asymmetric model of ARDL yields valid results to draw further inference.

Finally, the asymmetric impact in the long and short run examined, by the Wald test via checking the null hypothesis of symmetry against the alternative of as asymmetry. The results presented in the table 8 shows the significance of asymmetry in the short-run and long-run parameter. Only financial inclusion is detected to adjust at ten percent significance level. This implies that, taking the nonlinearity and asymmetry into account is important both in the short-and long-run with regards to financial inclusion. It is concluded that financial inclusion has asymmetric effect on financial stability in the short and long run.

\section{Discussion of Findings}

The evidence in this study indicates that, there is an existence of a long-run relationship between candidate variables of interest, such financial inclusion, financial efficiency and financial stability using both symmetric approach and asymmetric approach of econometric test (ARDL technique). Linear technique of econometric test unveils that, in the short-run, an improvement in financial inclusion stimulates the rate of financial stability, and modification of this variable to become non-linear model showed that the short-run positive effect and negative effect, including long-run decrease in financial inclusion enhance financial stability in this economy. It implies that, the more less privileged and the poor could have access to finance with fair price without discrimination, the more financial sector tend to stabilize. More so, extension of lending to smaller business enterprises could cushion the rate of volatility in the financial sector, as the number of smaller depositors in the economy would rise promoting large deposit base. This directly or indirectly reduces dependency of financial sector on financing non-core economic activities.

Furthermore, the linear technique of econometric test proclaims opposite relationship between financial efficiency and financial stability, in the short-run period. Similarly, the non-linear approach displays that negative effect of financial efficiency has adverse effect on the success of financial stability. These estimates supported Carneiro (2011) who establishd presence of trade-off between financial efficiency and financial stability. His study argued that low income economies with less efficient, less globally integrated and more capitalized financial system tend to be more 
protected against financial crisis while opposite is the case of high-income economies. Alber (2016) clarified Carneiro (2011), who conducted finding on impact of banking efficiency on financial stability in 15 MENA countries with conclusion that, both metrics are conflicting goals advising financial institutions to come up with strategies taking into account such conflicts.

Other outcomes suggest that, both ARDL approach and NARDL approach of econometric test exhibit that better and improved monetary policy has high probability to accelerate financial stability in this economy i.e. the estimated coefficients of monetary policy bore positive signs either in the short-run or long-run in both econometric tests. This signals that if there is a better and improved financial inclusion, such would contribute to a better transmission of monetary policy. There is high tendency that greater financial stability could be promoted through a better transmission of monetary policy. Surprisingly, inclusive growth and financial stability have negative relationship which implies that poor inclusive growth could dwindle the growth of financial instability. It is an indication that the experienced growth rates in this economy are attributed to those actions of a minority of the economic agents in societies where distributions of the gains from economic growth and better financial development have been restricted to the small segment of the society. This tends to heighten draining of economic resources including, welfare activity without specific input into productivity, which in turn threaten and impede sustainable economic development of the economy.

\section{Concluding Remarks}

This paper studies empirically the role of financial inclusion and financial efficiency towards financial stability in Nigeria, using quarterly time series data for the sample periods from 2000Q1 to 2018Q4 by means of the symmetric ARDL approach and asymmetric ARDL approach. This approach is explored to detect interaction between these financial variables, including monetary policy and inclusive growth as intervening variables. The outcomes of the finding indicate that our model could adopt non-linear autoregressive lags (NARDL) model, which allows us to decompose our candidate variables of interest to appreciate whether positive shock and negative shock in financial inclusion and financial efficiency had symmetric or asymmetric effects on financial stability. In addition, to proven the existence of a short-run and long-run asymmetric relationship between financial inclusion, financial efficiency and financial stability in Nigeria.

However, financial inclusion, including effective monetary policy are among parameters that complement the heightened magnitude of financial stability, while financial efficiency is a metric which is being a trade-off with financial stability in Nigeria based on our findings. Although, Carneiro (2011) wisely reiterates that, an economy is not be praised as a result of its national financial system, which is proud of its stability and its resilience to financial crisis, except the system efficiently provides financial intermediation that enhances economic growth, even inclusive growth and the greater welfare of the nation. The policy implication is that there is a need for policy-makers, governmental agencies, and monetary authority, including bodies associated with financial matters to focus their effort towards increasing financial accessibility of poor and vulnerable economic agents. To attain a stable financial system and a sustainable welfare in this economy, more efforts should be intensified towards improved schemes and strategies to transform the economy from informal sector into formal sector by extending financial services to weak economic agents, including those in the rural areas of the country, and participation of greater proportion of the population should not be managed and handled by corrupt hands or loosed hands. To achieve these, monetary authority needs to follow prudent and adequate supervisory standard in pursuing financial inclusion, financial intermediaries should be accompanied with good institutional quality and more importantly, financial awareness should be enhanced through financial teachings in all sectors both in the urban and rural areas of the economy.

\section{References}

Abler Nader (2016). Banking Efficiency and Financial Stability: Which Causes Which? - A Panel Analysis. A paper Presented in the International Conference on Applied Economics (ICOE). Nicosia, Cyprus. 
Raji Quantitative Economics and Management Studies (QEMS), 2021, 2(1): 72-84

Aahmed, M. M., and Mallick, S. K. (August 2017). Is financial Inclusion Good for Bank Stability? International evidence. Journal of Economic Behavior \& Organization. Retrieved from https://doi.org/10.1016/j.jebo.2017.07.027

Al-Smadi M.O.(2018). The Role of Financial Inclusion in Financial Stability: Lesson from Jordan. Banks and Bank Systems, 13(4), 31-39. doi:10.21511/bbs.13 (4).2018.03

Barik, R and Pradhan, A. K. (2020). Does Financial Inclusion Affect Financial Stability: Evidence From Brics Nations?The Journal of Developing Areas. Volume 55 No. 1 Winter 2021 Access provided at 16 Oct 2020 14:26 GMT from Macquarie University]

Carneiro Fábio Lacerda(2011). Is There Evidence of a Trade-Off between Financial Stability and Efficiency of Financial Intermediation? Preliminary Insights from the Global Financial Crisis of 2007-200. Weatherhead Center for International Affairs Harvard University

Dienillah, A., Anggraeni. L and Sahara. (2018). Impact of Financial Inclusion on Financial Stability Based on Income Group Countries. Bulletin of Monetary Economics and Banking, Bank Indonesia, 20(4), 1-14.

Elsherif, N. (2019). Financial Inclusion, Shadow Economy and Financial Stability: Evidence from Emerging Economies. [Master's thesis, the American University in Cairo]. AUC Knowledge Fountain. https://fount.aucegypt.edu/etds/520

Evans, O. (2016). The Effectiveness of Monetary Policy in Africa: Modeling the Impact of Financial Inclusion. Iranian Economic Review, 20(3), 327-337

Han, R and M Melecky (2013). Financial Inclusion for Financial Stability: Access to Bank Deposits and the Growth of Deposits in the Global Financial Crisis. World Bank Policy Research Working Paper 6577. Washington, DC: World Bank

Jimoh, A.T., Shittu, A.T and Attah, J.A. (2019). Impact of Financial Inclusion on Performance of Banks In Nigeria, Fountain University Osogbo Journal of Management (FUOJM), 2019, 4(3), 84 - 96

Le, Thai-Ha, Chuc, Anh Tu, Farhad Taghizadeh-Hesary.(2019). Financial Inclusion and its Impact on Financial Efficiency and Sustainability: Empirical evidence from Asia Borsa_Istanbul Review 19-4 (2019) 310e322

Lenka, S. K., and Bairwa, A. K. (2016). Does Financial Inclusion Affect Monetary Policy in SAARC countries? Cogent Economics \& Finance, 4(1), 1127011

Morgan, P. and Pontines, V. (2014). Financial Stability and Financial Inclusion. Retrieved on 26 July 2018. ADBI Working Paper Series, No.488. Availableat: https://papers.ssrn.com/sol3/papers.cfm?abstract_id11/42464018

Neaime, S., and Gaysset, I. (2018). Financial Inclusion and Stability in MENA:Evidence from Poverty and Inequality. Finance Research Letters, 24, 230e237.

Pesaran, M. H., Shin, Y. and Smith, R. J. (2001). Bounds Testing Approaches to the Analysis of Level Relationships. Journal of Applied Econometrics, 16, 289-326

Pham, M. H., and Doan, T. P. L. (2020). The Impact of Financial Inclusion on Financial Stability in Asian Countries. Journal of Asian Finance, Economics, and Business, 7(6), 47-59.

Sahay, R., Čihák, M., N’Diaye, P., Barajas, A., Mitra, S., Kyobe, A., and Yousefi, S. (2015). Financial Inclusion: Can It Meet Multiple Macroeconomic Goals? (17th ed.Vol. 15, IMF Staff Discussion Note). IMF. Retrieved from https://www.imf.org/external/pubs/ft/sdn/2015/sdn1517.pdf

Sarma, M. (2008). Index of Financial Inclusion. Indian Council for Research on International Economic Relations. Working Paper No. 215.

Shen, C. H., and Chen, T. H. (2014). Performance Analysis of Liquidity Indicators As Early Warning Signals. HKIMR Working Paper No.30/2014. Retrievedon 17th May, 2019. Available at: http://www.hkimr.org/uploads/ publication/404/wp-no-30_2014-final-.pdf. 
Raji Quantitative Economics and Management Studies (QEMS), 2021, 2(1): 72-84

Shin, Y., Yu, B., Greenwood and Nimmo, M. (2011). Modeling Asymmetric Cointegration and Dynamic Multiplier in a Nonlinear ARDL Framework, Mimeo

Siddik, N. A., and Kabiraj, S. (2018). Does Financial Inclusion Induce Financial Stability? Evidence from Crosscountry Analysis. Australasian Accounting, Business and Finance Journal, 12(1), 34-46. Retrieved fromhttp://ro.uow.edu.au/cgi/viewcontent.cgi?article=1831\&context=aabfj

Widarwati, E., Sari, P., and Nurmalasar, I, N.(2019).Role of Financial Inclusion to Stability: The Case of Indonesia's Sharia Banking HOLISTICA Vol.10, Issue 1, 2019, pp. 7-15 